\title{
MULTIVARIABLE ROBUST GRID CURRENTS CONTROL OF A SQUIRREL CAGE INDUCTION GENERATOR CONNECTED TO A WIND TURBINE
}

\author{
H. Hachemi*, H. Merabet Boulouiha**, A. Allali* , A. Tahr*; A. Taibi***, \\ ${ }^{*}$ Department of Electrotechnical, Faculty of Electrical Engineering, \\ LDDEE, (Laboratoire de Développement Durable de l'Energie Electrique) \\ University of Science and Technology of Oran Algeria, USTO_MB \\ ** Department of Electrical Engineering, University Centre of Relizane Algeria \\ ${ }^{* * *}$ IUT de Tremblay en France Paris 8 France \\ h.hachemi@yahoo.fr, houari.merabet@gmail.com, allalia@yahoo.com, alitahri.dz@gmail.com, taibi@iu2t.univ-paris8.fr
}

\begin{abstract}
In this paper, a multivariable robust control strategy of a variable speed wind energy conversion system based on a squirrel cage induction generator (SCIG) is presented. Optimal speed control of the SCIG is achieved by a conventional PI controller combined with a Maximum Power Point Tracking (MPPT) strategy. The Indirect Field Oriented Control (IFOC) technique based on a simple Park $(d-q)$ reference model is used to implement the proposed controller.

Active and reactive power flow between the grid and the inverter is controlled via simultaneous $H$-infinity control of active and reactive currents of the grid and the DC link voltage. The switching technique of the inverter which is connected directly to the grid is controlled by a programmed PWM look-up table wave shaping.

The robustness and performance of the proposed control scheme is evaluated on a comprehensive model of the wind energy conversion system using Matlab/Simulink.
\end{abstract}

Keywords- Renewable energy, asynchronous generator, IFOC, MPPT, programmed PWM, Matlab, Simulink, SimPower Systems toolbox.

\section{INTRODUCTION}

The ever-increasing energy demands, the decline of fossil fuels sources and global concerns on environmental issues related to climate change and $\mathrm{CO}_{2}$ emissions have been the driving force behind the production of electricity using renewable energy sources.

Renewable energy such as solar, wind, tidal currents and ocean clean energy is sustainable, inexhaustible and environmentally friendly. Wind energy is currently amongst the fastest-growing sources of the electricity in the world and its integration to the grid is the subject of active research and developments [1].

Amongst the various types of generators used for wind energy conversion system (WECS) [2], the squirrel-cage induction generator offers the advantages of high reliability, low maintenance requirements and cost, and is very light[3].

The amount of power generated from a wind energy conversion system depends mainly on the wind speed conditions and the geographical location. MPPT methods allow variable-speed wind turbines to operate at their optimal speed to capture the maximum power from the available wind energy [5]. Several MPPT techniques have been proposed for variable-speed WECS. The method used in this work is based on the knowledge of the wind turbine characteristics. Points of maximum power are stored in a look-up table as a function of the captured wind speeds. The optimal speed output from the MPPT is then used as the reference for the IFOC scheme [6].The controllers' parameters are obtained by the pole placement method.
The switching states of the converter on the generator side are controlled by a conventional PWM (sine-triangle).

The AC side converter, on the other hand, is controlled by a programmed PWM look-up table wave shaping and controls both the level of the DC voltage and the active $i_{d}$ and reactive $i_{q}$ currents and subsequently the power flow to the utility grid. The reference voltage on the DC side is chosen greater than the forward voltage of the source whereas the reference of the reactive current is set to zero to ensure power flow with unity power factor.

In this paper, a robust multivariable controller based on $\mathrm{H}$-infinity is designed and evaluated on the comprehensive model of the WECS.

The rest of the paper is organized as follows: Section 2 introduces the overall simulation model structure and develops the control strategies. Section 3 presents the mathematical models of the components of the system. Section 4 presents the $\mathrm{H}$-infinity control design and its modelling. Finally, the simulation results and conclusions are summarised in Sections 5 and 6, respectively. Appendix includes the values of the model parameters of simulation.

\section{DESCRIPTION THE WIND ENERGY CONTROL SYSTEM}

The WECS model consists of a three-bladed wind turbine of radius Rand a variable-speed SCIG connected to the supply through two PWM AC to DC controlled converters as shown in Fig.1. The converter next to the generator is used as a sine-triangle PWM rectifier to ensure power flow from the asynchronous generator's AC side to 


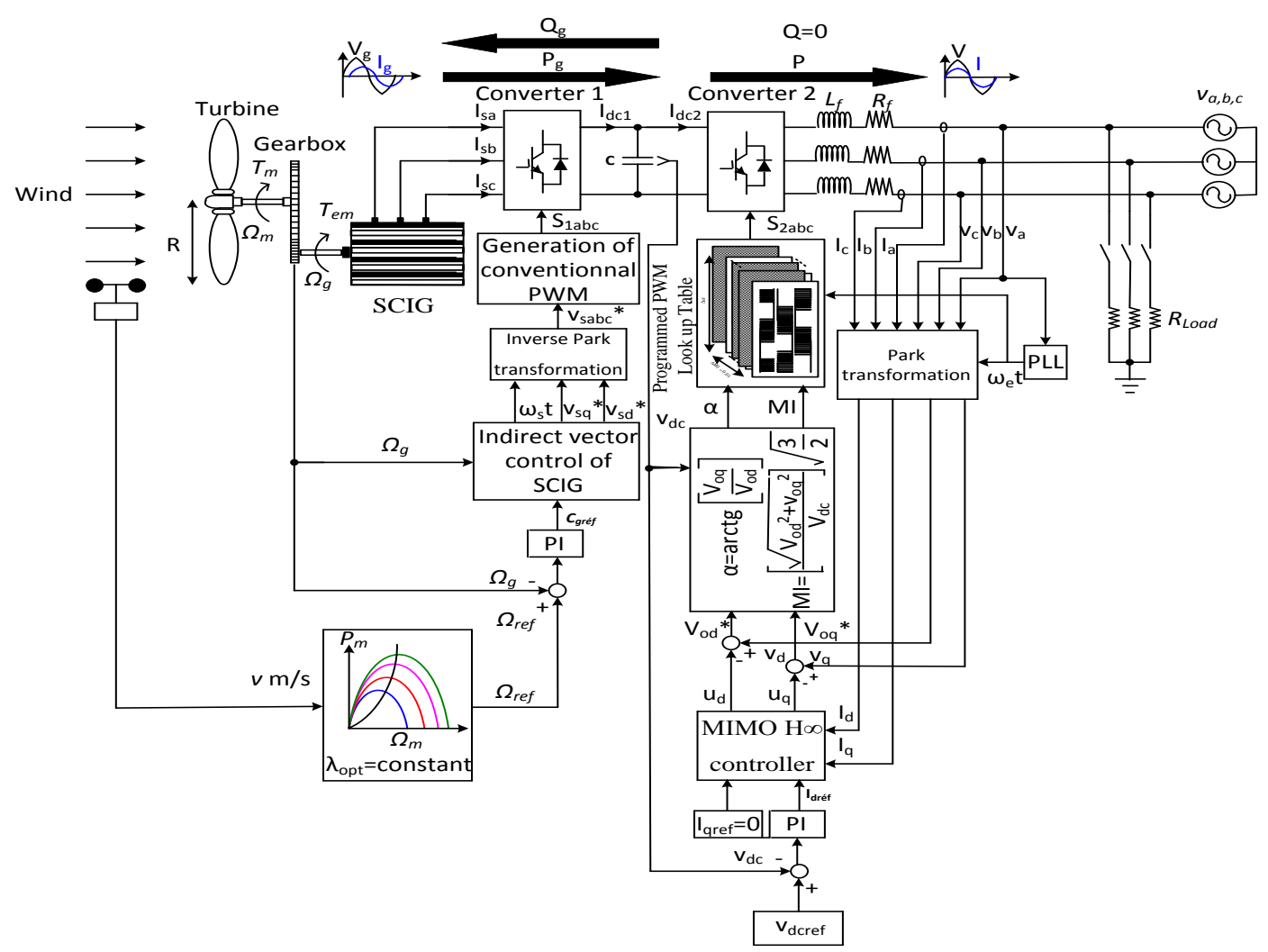

Fig. 1 The proposed circuit of controlling of wind based asynchronous squirrel cage generator

the DC side. The reference of the DC bus voltage is choen greater than the forward voltage to ensure power flow to the utility grid side.The author presents his main ideas, mathematical formulations and their derivation. This part should be accompanied by exact references. The converter next to the induction generator is used for controlling both the amplitude of the DC side voltage, and the active and reactive power flow by adjusting two parameters of the programmed PWM look-up table, namely, the modulation index (MI) and the phase shift $(\alpha)$ between the voltage and current of the utility grid.

For the control system to be efficient, it is necessary to get the amplitude of the DC side voltage as well as both voltages and currents of the AC side. Moreover, a phase locked-loop circuit (PLL) is used to synchronise the system d-q components of the AC side voltage and currents with the utility grid.

The control law of the MIMO H-infinity controller is obtained as:

Where:

$$
\left\{\begin{array}{l}
u_{d}=v_{d}-v_{o d} \\
u_{q}=v_{q}-v_{o q}
\end{array}\right.
$$

$v_{d}, v_{q}$ : are the grid voltages and $v_{o q}, v_{o d}$ : are the inverter output voltages.

$$
\text { Therefore: } \quad\left\{\begin{array}{l}
v_{o d}=v_{d}-u_{d} \\
v_{o q}=v_{q}-u_{q}
\end{array}\right.
$$

\section{MODELNG OF THE WECS COMPONENTS}

\subsection{Wind Turbine and MPPT Models}

The relationship between the wind speed and the mechanical aerodynamic transmission extracted from the wind can be described as follows [7-11]:

$$
P_{m}=\frac{1}{2} \rho \cdot \pi \cdot R^{2} \cdot C_{p}(\lambda, \beta) \cdot v^{3}
$$

With: $P_{m}$ : is the mechanical power of the wind turbine [W],

$\beta:$ is the orientation angle of the blades $\left[^{\circ}\right]$.

$\rho:$ is the density area $\left[\mathrm{kg} \cdot \mathrm{m}^{-3}\right]$.

$R$ : is the radius of the turbine [m].

$\mathrm{v}$ : is the wind speed $\left[\mathrm{m} . \mathrm{s}^{-1}\right]$

The power coefficient $C_{p}$ is used for defining the aerodynamic efficiency of the wind turbine and depends on the characteristics of the turbine [11].

$\lambda$ : is defined as the ratio between the linear velocity at the end of the blade and the wind speed of the free jet and is given by:

$$
\lambda=\frac{\Omega_{m} \cdot R}{v}
$$

Where $\Omega_{m}$ is the rotational speed of the turbine. The characteristics of the $C_{p}$ vary greatly depending on the wind and the speed level.

This means that the locus of the point representing the maximum power can be determined and tracked by adapting the speed of the turbine. Thus, to maximize the converted power, the turbine speed must be adapted to wind speed to follow the trajectory of the maximum power point given by equation $(2)[4,5]$.

\subsection{Generator and Grid utility Models}

Based on the equivalent circuit used for the induction machines in the Park frame, the following model for the two-phase stator winding equivalent can be obtained:

$$
\left\{\begin{array}{l}
v_{s d}=R_{s} i_{s d}-\omega_{s} \Phi_{s q}+\frac{d \Phi_{s d}}{d t} \\
v_{s q}=R_{s} i_{s q}+\omega_{s} \Phi_{s d}+\frac{d \Phi_{s q}}{d t}
\end{array}\right.
$$

Where $v_{s d}$ and $v_{s q}$ are the stator voltages in the Park frame, $\omega_{s}$ speed of the generator stator and $\Phi_{s d} \Phi_{s q} i_{s d} i_{s q}$ are 
respectively the flux and the stator currents components on the $\mathrm{d}$ and $\mathrm{q}$ axis of Park frame.

The electrical model for the two-phase equivalent rotor winding is:

$$
\begin{aligned}
& v_{r d}=0=R_{r} i_{r d}-\omega_{r} \Phi_{r q}+\frac{d \Phi_{r d}}{d t} \\
& v_{r q}=0=R_{s} i_{r q}+\omega_{s} \Phi_{r d}+\frac{d \Phi_{r q}}{d t}
\end{aligned}
$$

Similarly, rotor voltages $v_{r d}$ and $v_{r q}$ are set to zero for a short-circuited rotor. $\omega_{r}$ is the rotor speed of the generator and $\Phi_{r d}, \Phi_{r q}, i_{r d}$ and $i_{r q}$ are respectively the flux and currents of the rotor in $\mathrm{d}-\mathrm{q}$ frame axis.

The flux components in the $\mathrm{d}-\mathrm{q}$ frame axis are given by:

For the rotor

$$
\begin{aligned}
& \Phi_{s d}=L_{s} i_{s d}+L_{m} i_{r d} \\
& \Phi_{s q}=L_{s} i_{s q}+L_{m} i_{r q}
\end{aligned}
$$

And the motion equation is:

$$
\begin{aligned}
& \Phi_{r d}=L_{m} i_{s d}+L_{r} i_{r d} \\
& \Phi_{r q}=L_{m} i_{s q}+L_{r} i_{r q}
\end{aligned}
$$

$T_{e m}$ : The electromagnetic torque [N.m].

$$
T_{e m}-T_{m}=f . \Omega_{g}+J \frac{d \Omega_{g}}{d t}
$$

$T_{m}$ : The mechanical torque developed by the turbine [N.m].

The electromagnetic torque is expressed as:

$$
T_{e m}=p \frac{3}{2} \frac{L_{m}}{L_{r}}\left(\Phi_{r d} \cdot I_{s q}-\Phi_{r q} \cdot I_{s q}\right)
$$

The mathematical model of the grid utility in Park frame is:

$$
\frac{d}{d t}\left[\begin{array}{l}
i_{d} \\
i_{q}
\end{array}\right]=\left[\begin{array}{cc}
\frac{-R_{f}}{L_{f}} & \omega_{s} \\
-\omega_{s} & \frac{-R_{f}}{L_{f}}
\end{array}\right]\left[\begin{array}{l}
i_{d} \\
i_{q}
\end{array}\right]+\frac{1}{L_{f}}\left[\begin{array}{l}
v_{d}-v_{o d} \\
v_{q}-v_{o q}
\end{array}\right]
$$

Where:

$\omega_{e}$ : is the angular frequency of the grid.

The DC bus voltage $v_{d c}$ varies with the power exchanged between the turbine and the grid according to the following equation:

$$
C \frac{d v_{d c}}{d t}=I_{d c}=I_{d c 1}-I_{d c 2}
$$

Where:

$I_{d c l}$ is the DC side generator converter current.

$I_{d c 2}$ is the DC side grid converter current.

The active and reactive powers of the grid in relationship with Park frame voltages and currents components, where $v_{q}=0$, are:

$$
\left\{\begin{array}{l}
P=\frac{3}{2} v_{d} \cdot i_{d} \\
Q=\frac{3}{2} v_{d} \cdot i_{q}
\end{array}\right.
$$

The active power transmitted by the DC link can be expressed by:

$$
P_{d c}=v_{d c} . I_{d c}
$$

The power balance between the $\mathrm{DC}$ and $\mathrm{AC}$ gives:

$$
P_{d c}=P \quad \Rightarrow \quad v_{d c} \cdot I_{d c}=\frac{3}{2} v_{d} \cdot i_{d}
$$

\subsection{Generation of the programmed PWM Look up Table Models}

This PWM technique is used to calculate the switching instants of the devices so as to match certain criteria on the frequency spectrum of the resulting wave [12]. These sequences are then stored and used cyclically to ensure the control of the switches.

The criteria commonly used are:

- Elimination of harmonics of a certain range

- Elimination of harmonics in a specified frequency band.

A Simulink block was created for the programmed PWM technique [10].

The MI is varied from 0 to1.15 in steps of 0.01 (i.e. 115 is the value of MI). Each MI is shown in a table of $\omega t$ for a period of0.02 sec with a sampling time of 0.02/4096.

The solutions obtained by the Newton-Raphson method to eliminate ten (10) harmonics for each MI is stored in an array of size 4 Kbytes $(4 \times 1024=4096)$ i.e. 4096 points per cycle.

Thus, two counters were designed (one, horizontally to detect the MI and the other vertically to detect the instant $\omega t+\alpha$ and to count from that instant for a period of 0.02 sec in steps of 0.02 / 4096), where the first counter pointer detects the MI. Once the MI is detected, the pointer of the second counter is attached to the table for the MI obtained by the first counter from the time $\omega t+\alpha$ as shown in Fig. 2 .

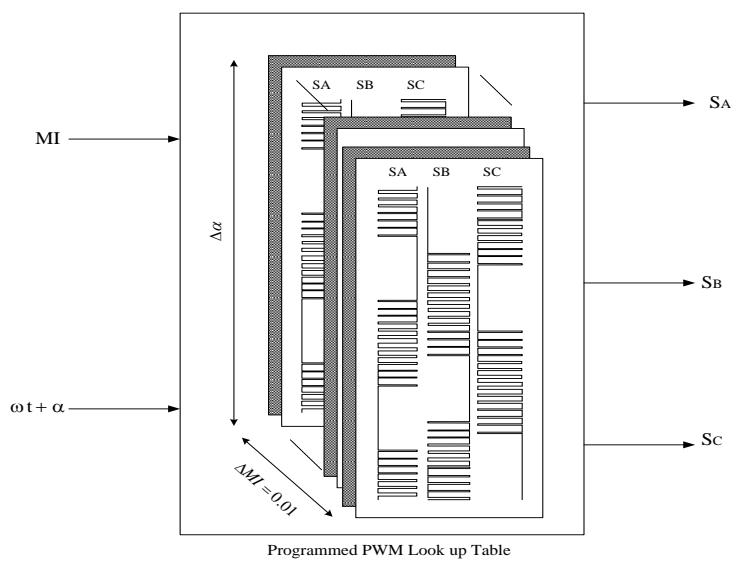

Fig. 2 Programmed PWM look-up table generation method

\section{H-INFINITY MIMO CONTROLLER DESIGN}

The Hळ standard problem can be formulated using the basic process model-controller structure depicted in Fig. 3.

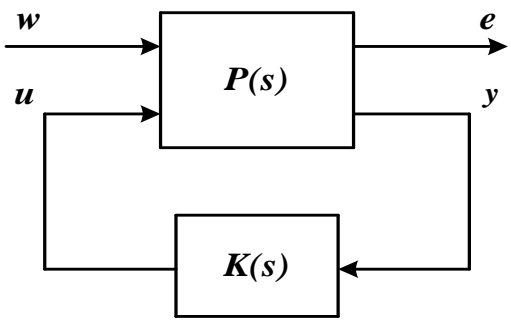

Fig. $3 \mathrm{H}_{\infty}$ standard problem. 
The transfer function relating $\mathrm{w}, \mathrm{u}, \mathrm{e}$ and $\mathrm{y}$ is given by:

$\left[\begin{array}{l}E(s) \\ Y(s)\end{array}\right]=P(s)\left[\begin{array}{l}W(s) \\ U(s)\end{array}\right]=\left[\begin{array}{ll}P_{11}(s) & P_{12}(s) \\ P_{21}(s) & P_{22}(s)\end{array}\right]\left[\begin{array}{c}W(s) \\ U(s)\end{array}\right]$

$\mathrm{P}$ is the transfer function of the process and $\mathrm{K}$ is the $\mathrm{H}_{\infty}$ controller to be designed.

The transfer matrix between $\mathrm{w}$ and e of the closed loop system, known as the Linear Fractional Transformation (LFT) which is given by:

$$
F(P, K)=P_{11}+P_{12} \cdot K\left(I_{n}-P_{22} \cdot K\right)^{-1} \cdot P_{21}
$$

Different methods have been being proposed to solve the H-infinity standard problem. In this paper, the GloverDoyle algorithm has been used [13-14]. We introduce a minimal realization of the system $\mathrm{P}(\mathrm{s})$ as follows: $P(s)=\left[\begin{array}{ll}P_{11}(s) & P_{12}(s) \\ P_{21}(s) & P_{22}(s)\end{array}\right]=\left[\begin{array}{ll}D_{11} & D_{12} \\ D_{21} & D_{22}\end{array}\right]\left[\begin{array}{l}C_{1} \\ C_{2}\end{array}\right] \cdot\left(s \cdot I_{n}-A\right)^{-1}\left(\begin{array}{ll}B_{1} & B_{2}\end{array}\right)$

This result is associated with the following internal description (where $\mathrm{x}$ is the state vector):

$$
\left\{\begin{array}{c}
\dot{x}(t)=A \cdot x(t)+B_{1} \cdot \omega(t)+B_{2} \cdot u(t) \\
e(t)=C_{1} \cdot x(t)+D_{11} \cdot \omega(t)+D_{12} \cdot u(t) \\
y(t)=C_{2} \cdot x(t)+D_{21} \cdot \omega(t)+D_{22} \cdot u(t)
\end{array}\right.
$$

\section{Where:}

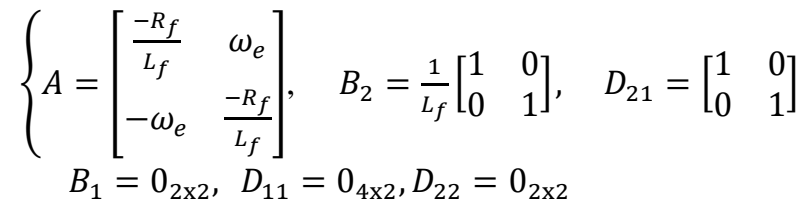

With:

To solve the Hळ standard problem, we assume that the following assumptions are satisfied:

The matrices $\left(\mathrm{A}, \mathrm{B}_{2}, \mathrm{C}_{2}\right)$ have to be controllable and observable in order to guarantee the existence of a controller $\mathrm{K}$ that internally stabilizes the system. The feedback controller $\mathrm{K}_{\mathrm{c}}$ is designed to make the system internally stable and minimize the $\mathrm{H} \infty$ norm of the transfer function from the perturbation w to the error signal $\mathrm{e}$.

$$
\left\|\mathcal{F}\left(P, K_{c}\right)\right\|_{\infty} \prec \gamma
$$

For $e=C x$, the $\mathrm{H} \infty$ state regulator has the following form:

$$
\left\{\begin{array}{l}
u=-K_{c} \cdot x \\
K_{c}=B^{T} \cdot X
\end{array}\right.
$$

The equation of the controller must satisfy the Riccati equations:

$$
A^{T} \cdot X+X \cdot A+X\left(\gamma^{-2} \cdot B_{1} \cdot B_{1}^{T}-B_{2} \cdot B_{2}^{T}\right) X+C_{1}^{T} \cdot C_{1}=0
$$

According to the bounded real lemma, such a nonnegative definite solution $\mathrm{X}$ exists if the condition

$$
\min _{\text {Kstabilizing }}\left\|\mathrm{F}\left(P, K_{c}\right)\right\|_{\infty}<\gamma \text { is satisfied. }
$$

The $\mathrm{H} \infty$ controller calculated is in the following form:

$$
K(s)=\left[\begin{array}{cc}
k_{1}(s) & 0 \\
0 & k_{2}(s)
\end{array}\right]
$$

With:

$$
\begin{aligned}
& k_{1}(s) \\
& =\frac{-5.6522\left(s+10^{5}\right)(s+5341)\left(s^{2}+2160 s+1.4 * 10^{6}\right)}{(s+0.1)\left(s^{2}+10620 s+2.82 * 10^{7}\right)\left(s^{2}+2321 s+1.452 * 10^{6}\right)}
\end{aligned}
$$

$$
\begin{aligned}
& \mathrm{k}_{2}(\mathrm{~s}) \\
& =\frac{18.6212\left(\mathrm{~s}+10^{5}\right)(\mathrm{s}+5308)\left(\mathrm{s}^{2}+2194 \mathrm{~s}+1.288 * 10^{6}\right)}{(\mathrm{s}+0.1)\left(\mathrm{s}^{2}+10620 \mathrm{~s}+2.82 * 10^{7}\right)\left(\mathrm{s}^{2}+2321 \mathrm{~s}+1.452 * 10^{6}\right)}
\end{aligned}
$$

\section{SIMULATION RESULTS}

The parameters values of all the components used in the simulation are listed in the Appendix. Fig. 4 shows the active and reactive powers of the generator and the three phase stator voltages. Before the action of the wind turbine, it can be seen that the active power reaches a low value due to the iron and copper losses of the generator. When the wind turbine starts operating at $\mathrm{t}=0.2 \mathrm{~s}$, the generator supplies an active power equal to $-2 \mathrm{Kw}$ for a wind velocity of $12 \mathrm{~m} / \mathrm{s}$. At $\mathrm{t}=1.4 \mathrm{~s}$ the wind velocity was changed to $\mathrm{v}=8 \mathrm{~m} / \mathrm{s}$, then the active power falls to $0.6 \mathrm{Kw}$. The reference of the active power is provided by the MPPT algorithm according to the available wind speed.

Fig. 5 shows the wind speed, the speed and electromagnetic torque and the three phase stator currents of the generator for the same changes in the available wind. We note that the angular velocity and the electromagnetic torque are always monitored according to the value of the wind speed captured.

Fig. 6 shows the active and reactive power and the grid and load currents. From time $t=0.2 \mathrm{~s}$ to $\mathrm{t}=0.8 \mathrm{~s}$ the active power is the same as the active power supplied by the generator, at $\mathrm{t}=0.8 \mathrm{~s}$ a resistive load of $2 \mathrm{Kw}$ is applied to the grid. The grid currents are constants and reach zero and the load absorbs all the power supplied by the generator. When the wind speed changes from $12 \mathrm{~m} / \mathrm{s}$ to $8 \mathrm{~m} / \mathrm{s}$ at $\mathrm{t}=1.4 \mathrm{~s}$, the generator is supplying a low current which forces the grid to produce the critical power to the load. The reactive power is always nil because the reactive power reference is set to zero to obtain a unity power factor.
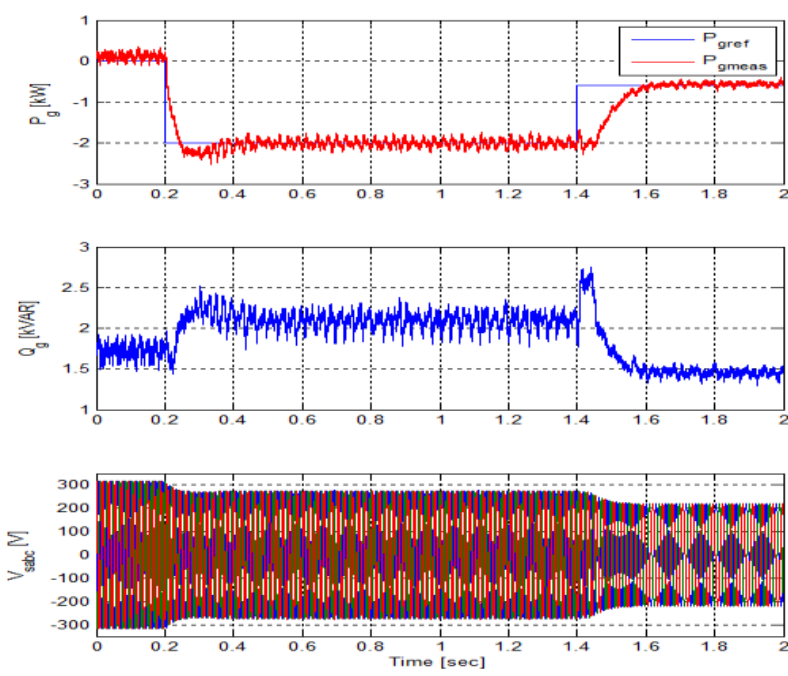

Fig. 4 Active and reactive power of the generator and three phase stator voltages. 

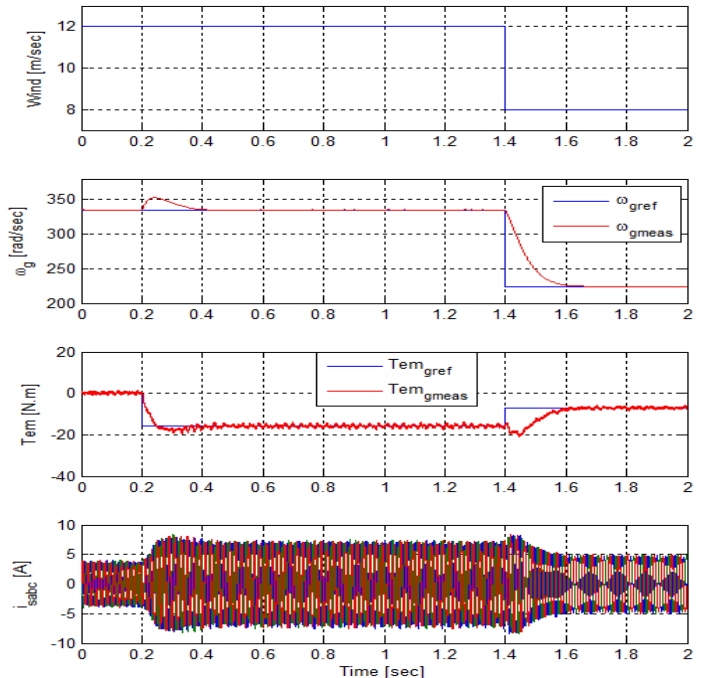

Fig. 5 Wind speed, generator angular velocity, electromagnetic torque and three phase currents.

Fig.7 shows the responses of the voltage waveform and power. It can be noted that the DC voltage reference is maintained at $800 \mathrm{~V}$ after a short transient despite changes in wind speed from 12 to $10 \mathrm{~m} / \mathrm{sec}$. The power and current of the DC side is almost zero in steady state.
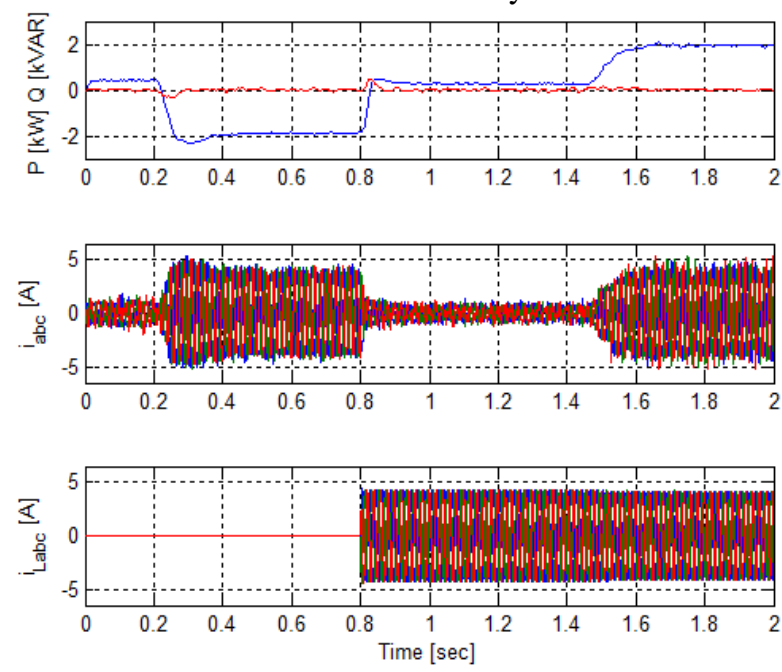

Fig. 6 Active and reactive power of the grid, grid and load phase currents.
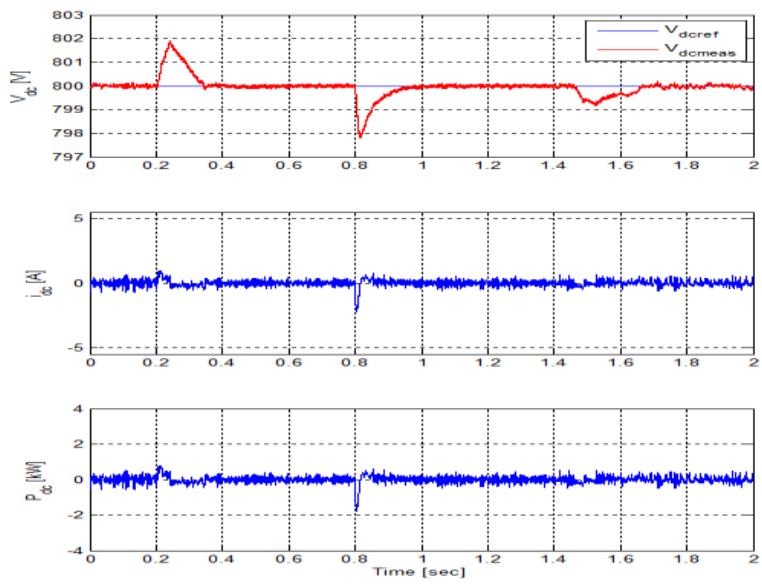

Fig. 7 DC link voltage, current and power waveforms.

Fig. 8 shows responses of the power coefficient $C_{p}$ and the tip speed ratio $\lambda$. We note that the power coefficient is maintained at its maximum value of 0.411 when the speed $\lambda$ remains at the maximum value of 8 .
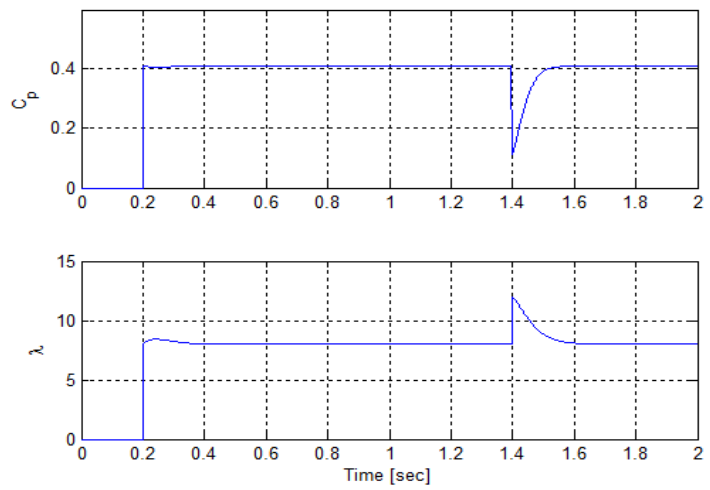

Fig. 8 Reponses of the power coefficient $C_{p}$ and tip speed ratio $\lambda$.

\section{CONCLUSION}

In this paper, a robust control scheme was applied to grid currents of squirrel cage induction generator connected to a wind turbine. The MPPT control gives the optimal speed according to wind speed available. This optimal speed was taken as the reference of the indirect field oriented control of the induction generator. Active and reactive power flow between the inverter and the grid was controlled by the state space $\mathrm{H}$-infinity controller based on Riccati equation. The inverter used a programmed PWM look up table which minimized considerably the harmonics in grid voltage and current.

The dynamic performance of the system was improved by the control strategy proposed in this work; the control scheme was able to extract the maximum of power from the wind as shown in the simulation tests. As future work, the authors believe that the dynamic performance can be improved by using the space vector PWM technique with multilevel converters.

\section{REFERENCES}

[1] RECHSTEINER, R.: Wind power in context-A clean revolution in the energy sector, Energy Watch Group Report, 2008.See also www.energywatchgroup.org.

[2] DOMÍNGUEZ-GARCÍA, J. L. - GOMISBELLMUNT, O. - TRILLA-ROMERO, L. JUNYENT-FERRÉ, A.: Vector control of squirrel cage induction generator for wind power, Electrical Machines (ICEM), 2010 XIX International Conference on, vol., no., pp.1-6, 6-8 Sept. 2010 doi: 10.1109/ICELMACH.2010. 5608021

[3] HAEJOON, A. - HEESANG, K. - HONGWOO, K. - HYUNGOO, K. - SEOKWOO, K. - GILSOO, J. BYONGJUN, L.: Modeling and voltage-control of variable-speed SCAG-based wind farm, Renewable Energy, Volume 42, June 2012, Pages 28-35, ISSN 0960-1481, 10.1016/j.renene.2011.09.029.

[4] MERABET BOULOUIHA, H. - ALLALI, A. TAHRI, A. - DRAOU, A. - DENAI, M.: A simple maximum power point tracking based control strategy applied to a variable speed squirrel cage induction 
generator J. Renewable Sustainable Energy 4, 053124 (2012), doi:10.1063/1.4763562

[5] MOOR, G. D. - BEUKES, H. J.: Maximum power point trackers for wind turbines, Power Electronics Specialists Conference, 2004. PESC 04. 2004 IEEE 35th Annual, vol.3, no., pp. 2044- 2049 Vol.3, 20-25 June 2004, doi: 10.1109/PESC.2004.1355432

[6] DOMÍNGUEZ-GARCÍA, J. L. - GOMISBELLMUNT, O. - TRILLA-ROMERO, L. JUNYENT-FERRÉ, A.: Vector control of squirrel cage induction generator for wind power, Electrical Machines (ICEM), 2010 XIX International Conference on, vol., no., pp.1-6, 6-8 Sept. 2010. DOI: 10.1109/ICELMACH.2010. 5608021

[7] RAI, C. K.: Non Conventional Energy Sources of Energy, Khanna Publishers, New Delhi, 1996.

[8] LEI, Y. - MULLANE, A. - LIGHTBODY G. YACAMINI R.: Modeling of the Wind Turbine with a Doubly Fed Induction Generator for Grid Integration Studies, IEEE Transactions on Energy Conversion, Vol.21,No1, March 2006,pp.257-264.

[9] KUPERMAN, A. - RABINOVICI, R. - WEISS, G.: A shunt connected inverter based variable speed wind turbine generation, Int. jour. of electromotion, vol. 13, no. 1 , pp. 67-72, 2006.

\begin{tabular}{ll}
\hline \hline Tubine & \\
\hline \hline Densityarea, $\rho\left[\mathrm{kg} \cdot \mathrm{m}^{-2}\right]$ & 1.225 \\
Nominal mechanical power, $P_{m, n}[\mathrm{~kW}]$ & 2.68 \\
Radius of the turbine, $R[\mathrm{~m}]$ & 1.4 \\
Nominal wind speed, $v_{n}\left[\mathrm{~m} \cdot \mathrm{s}^{-1}\right]$ & 12 \\
Gain of the multiplier, $G$ & 2.4453512 \\
\hline \hline SCIG & 2 \\
\hline Nominal power, $P_{g, n}[\mathrm{~kW}]$ & 50 \\
Nominal frequency, $f_{g, n}[\mathrm{~Hz}]$ & 4.85 \\
Stator resistance, $R_{s}[\Omega]$ & 0.016 \\
Stator leakage inductance, $L_{l s}[\mathrm{H}]$ & 3.805 \\
Rotor resistance, $R_{r}[\Omega]$ & 0.016 \\
Rotor leakage inductance, $L_{l r}[\mathrm{H}]$ & 0.258 \\
Cyclic mutual inductance, $L_{m}[\mathrm{H}]$ & 0.031 \\
Inertia, $J\left[\mathrm{~kg} \cdot \mathrm{m}^{-2}\right]$ & 0.00114 \\
Viscousfriction coefficient, $f\left[\mathrm{~N} . \mathrm{m} . \mathrm{sec}^{-} \mathrm{rad}^{-1}\right]$ & 2 \\
Number of pole pairs, $p$ &
\end{tabular}

\begin{tabular}{ll}
\hline IFOC control block & \\
\hline Proportional gain of speed controller, $K_{p \Omega}$ & 1 \\
Integral gain of the speed controller, $K_{i \Omega}$ & 15.872 \\
\hline & \\
\hline DC side & $10^{4}$ \\
\hline Capacitance, $C[\mu \mathrm{F}]$ & 2 \\
Proportional gain of speed controller, $K_{p d c}$ & 25 \\
Integral gain of the speed controller, $K_{i d c}$ & \\
\hline Load & 2 \\
\hline Active power, $P_{\text {cha }}[\mathrm{kW}]$ & 0 \\
\hline Reactive power, $Q_{\text {cha }}[\mathrm{Var}]$ &
\end{tabular}

[10] GAGNON, R. - SAULNIER, B. - SYBILLE, G. GIROUX, P.: Modeling of a Generic HighPenetration No-Storage Wind-Diesel System Using Matlab/Power System Blockset, Global Windpower Conference, Paris, France, April 2002.

[11] MULJADI, E. - BUTTERFIELD, C. P.: "PitchControlled Variable Speed Turbine Generation", IEEE Trans. Ind. Appl., vol 37(1), pp. 240-246, 2001

[12] ENJETI, P. N. - ZIOGAS, P. D. - LINDSAY, J. F.: Programmed PWM techniques to eliminate harmonics: a critical evaluation., 26 Conference Record of the 1988 IEEE Industry Applications Society Annual Meeting 418 - 430 (1990). Ieee. DOI: 10.1109/ IAS. 1988.250955477)

[13] GLOVER, K. - DOYLE, J. C.: "State-Space Formulae for all Stabilizing Controllers That Satisfy an Hळ-Norm Bound and Relations to Risk Sensitivity". Systems \& Control Letters, vol. 11, pp. 167-172, 1988.

[14] DOYLE, J. C. - GLOVER, K. - KHARGONEKAR, P. K. - FRANCIS, B. A.: "Slate-Space Solutions to Standard H2 and Hळ Control Problems". IEEE Trans. Autom. Control, AC 34 no 8, pp. 831 -846, 1989

Appendix: Values of the Models Parameters

\begin{tabular}{ll}
\hline \hline Source & \\
\hline \hline Effective voltage, $\mathrm{V}_{\mathrm{s}}[\mathrm{V}]$ & 380 \\
Frequency, $\mathrm{f}_{\mathrm{s}}[\mathrm{Hz}]$ & 50 \\
\hline & \\
\hline \hline Transformer & 3.4 \\
\hline Leakage resistance, $\mathrm{R}_{\mathrm{f}}[\Omega]$ & 3.3 \\
\hline The leakage inductance, $\mathrm{Lf}_{\mathrm{f}}[\mathrm{mH}]$ & \\
\hline
\end{tabular}

Received September 19, 2015, accepted February 8, 2016

\section{BIOGRAPHIES}

Hachemi Hachemi was born in Ain Témouchent in Algeria in December 14 1967. In 1993 he graduated at the electrotechnics Department of the Faculty of Electrical Engineering at the University of Sciences and Technology of Oran in Algeria. He received the Magister degrees from the University of Sciences and Technology of Oran, Algeria in 2012 in electrical engineering. Is currently preparing a $\mathrm{PhD}$ thesis on the impact of introducing a multilevel inverter on a wind energy. His main research interests are renewable energy (solar and wind)

Houari Merabet Boulouiha was born in Oran in Algeria in April $25^{\text {th }} 1981$. He received the Ingeniorat d'Etat and the M.Sc. degrees from the University of Sciences and Technology of Oran, Algeria in 2005 and 2009 respectively all in electrical engineering. His main research interests are in the field of analysis, modeling and simulation of power converters, the renewable energy systems and advanced control. $\mathrm{He}$ is now pursuing his $\mathrm{PhD}$ degree at electrotechnics department of the University of Sciences and Technology (Oran, Algeria).

Ahmed Allali was born in Mecheria in Algeria in July $3^{\text {rd }}$ 1960. In 1987 he graduated at the electrotechnics Department of the Faculty of Electrical Engineering at the University of Sciences and Technology of Oran in Algeria. $\mathrm{He}$ received the M.Sc. and the $\mathrm{PhD}$ degrees from the University of Sciences and Technology of Oran, Algeria in 1990 and 2006 respectively all in electrical engineering. Director of LDDEE, Laboratory. His main research 
interests are in the field of a control and real time simulation of power systems, and the study and the location of FACTS and their influence on the electricity network and renewable energy (solar and wind)

Ali Tahri was born in El Biodh Naama in Algeria in February $9^{\text {th }} 1967$. He received the Ingeniorat d'Etat, the M.Sc. and the PhD degrees from the University of Sciences and Technology of Oran, Algeria in 1992, 1997 and 2006 respectively all in electrical engineering. His main research interests are in the field of analysis, modeling and simulation of power converters, the advanced static VAR compensation and FACTS systems and microcontrollers and embedded systems. He has co-authored in the "Power Electronics Handbook" edited by Dr. M.H.Rashid, with Academic Press in 2001. He is now an assistant professor at electrotechnics department of the University of Sciences and Technology (Oran, Algeria) and member of Sahara Solar Breeder project (SSB).

Ali Taibi was born in Mecheria, Algeria in october 21 1963. In 1987 he graduated at the electrotechnics Department at the University of Sciences and Technology of Oran in Algeria. He received the DEA from Electrical Engineering at Ecole Polytechnique Grenoble in 1988 and the PhD degrees at University of Franche-Comté (UFC) in1992 respectively all in electrical engineering.

His main research interests are in the field of power electronics and control and drive brushless motors without position sensor and asynchronous motors with vector control. In charge, teaching power electronics, electrical engineering, maintenance of technical systems, and automatic. Course director of Genie Industriel and Maintenance Department, University of Paris 8. 